\title{
Novas diretrizes curriculares para os cursos de graduação em Educação Física: oportunidades de aproximações com o SUS?
}

\author{
New curriculum guidelines for undergraduate Physical Education courses: \\ opportunities for approximation with SUS?
}

\section{AUTORES \\ Filipe Ferreira da $\operatorname{Costa}^{1}$ (D) \\ 1 Universidade Federal da Paraíba, Departamento de Educação Física, João Pessoa, Paraíba, Brasil. \\ CONTATO \\ Filipe Ferreira da Costa \\ filipefcosta@outlook.com \\ Prédio da Pós-graduação em Educação Física, sala 20, Universidade Federal da Paraíba, Cidade Universitária, João Pessoa, Paraíba, Brasil. CEP: 58051-900. \\ DOI}

$10.12820 /$ rbafs. $24 \mathrm{e} 0067$

\section{(cc) BY-NC-SA}

Este obra está licenciado com uma Licença Creative Commons Atribuição-NãoComercialCompartilhalgual 4.0 Internacional.
Desde meados dos anos 2000 a participação do profissional de Educação Física (PEF) nos serviços públicos de saúde vem se consolidando. A Educação Física é uma das cinco categorias mais frequentes no NASF e integra metade das equipes cadastradas ${ }^{1}$. Entre 2013 e 2017 houve um crescimento médio de $141 \%$ na participação deste profissional no Sistema Único de Saúde (SUS) ${ }^{2}$. Apesar desta aproximação, algumas evidências sugerem distanciamentos entre o perfil de atuação profissional e as demandas e processos de trabalho inerentes ao SUS.

Especificamente na atenção primária à saúde, a atuação do PEF tem centrado no atendimento de grupos de usuários com perfis específicos (idosos, hipertensos, diabéticos e gestantes), com a utilização de caminhadas, ginástica, alongamento e relaxamento como principais ferramentas de trabalho ${ }^{3}$. Associado à essa práxis, verifica-se um discurso preventivista e balizado pela racionalidade biomédica ${ }^{4}$, atribuindo à atividade física um status de "remédio" para para enfrentamento das doenças crônico-degenerativas por meio do combate ao sedentarismo. Essa abordagem, muitas vezes, reduz a intervenção do profissional ao modelo tradicional de prevenção em saúde ${ }^{5}$, caracterizado pelo foco em indivíduos expostos, com a finalidade de alertar sobre os riscos de um estilo de vida sedentário, utilizando estratégias educativas modeladoras, com transmissão unilateral de informação, esperando do usuário uma adesão a um comportamento desejado (pelo profissional). Além disso, há evidências de que os PEF têm dificuldades de apropriação de conceitos, processos e ferramentas de trabalho próprios da atenção à saú$\mathrm{de}^{6}$, pouco explorados na formação inicial, como a clínica ampliada, apoio matricial, acolhimento, vínculo, integralidade, longitudinalidade do cuidado, redes de atenção à saúde, trabalho em equipe e interprofissionalidade.

Esforços no sentido de discutir estas fragilidades e qualificar a intervenção do PEF no campo da saúde têm sido realizados, como a criação da Associação Brasileira de Ensino da Educação Física para a Saúde ${ }^{7}$ o estudo das competências próprias para a intervenção na atenção primária à saúde ${ }^{8}, \mathrm{o}$ apontamento de possíveis caminhos para atuação profissional do $\mathrm{PEF}^{9}$, bem como a necessidade de aproximação com o campo de conhecimento da Saúde Coletiva ${ }^{10}$. Todos eles perpassam necessariamente por mudanças nos currículos de formação inicial, e é nesta perspectiva que trarei alguns elementos para discussão.

Sabidamente, a formação inicial na Educação Física para a atuação no SUS é ainda incipiente. Embora existam experiências inovadoras de cur- 
sos de graduação com ênfase na área da saúde, como é o caso da Escola de Artes, Ciências e Humanidades EACH-USP Leste e da Universidade Federal de São Paulo (UNIFESP) Baixada Santista, o SUS ainda é pouco presente nos currículos da maioria dos cursos, disputando espaços com campos epistemológicos hegemônicos da Educação Física, notadamente a biodinâmica do movimento humano. Quando há alguma aproximação com o campo da saúde, esta parece balizar-se predominantemente no paradigma biomédico do exercício/atividade física. Isto ocorre como resultado do crescimento da área "atividade física e saúde" nos programas de pós-graduação em Educação Física, balizados fundamentalmente pela racionalidade e instrumental metodológico da epidemiologia, bem como pela já consolidada área da biodinâmica do movimento humano. Embora sejam importantes para dar visibilidade e justificar investimentos governamentais em programas de promoção da saúde e atividade física, o referencial teórico-metodológico destas duas áreas são insuficientes para alicerçar o saber-fazer no campo do trabalho no SUS.

É nesse contexto que as novas diretrizes curriculares elaboradas no âmbito do Conselho Nacional de Educação ${ }^{11}$ reacendem o debate sobre a formação inicial na comunidade acadêmica da Educação Física. Entendo que se trata de momento ímpar para a reflexão, discussão e ação no sentido de aproximar a Educação Física de uma formação mais adequada e integrada ao setor da saúde. Na resolução, retoma-se a ideia de formação de tronco comum (formação ampliada), com posterior definição da formação em licenciatura ou bacharelado (formação específica). E é na formação específica em bacharelado que se explicita a saúde como eixo articulador da formação, juntamente com os eixos do esporte, e da cultura e lazer. Neste eixo, são previstos temas diretamente associados a atuação do profissional no SUS, em seus diferentes níveis de atenção à saúde. Proponho aqui, a problematização e reflexão sobre seis aspectos que considero centrais para a discussão de mudanças na formação inicial para melhor atender às expectativas e exigências do campo da saúde.

Primeiro, considero que qualquer movimento de mudança deve atentar para o currículo como um todo, e não apenas incluir componentes curriculares isolados para atender às exigências das diretrizes. É necessário repensar toda a estrutura curricular, almejando formas de organização que superem uma estruturação baseada em conteúdos fragmentados e desarticulados, e avance para a promoção de competências profissionais amplas e relacionadas às demandas sociais e do mundo do trabalho, por meio de um currículo mais integrado, que articule ensino, pesquisa e extensão de maneira mais orgânica. Destaco o papel do contato precoce e constante do graduando com os cenários de prática, não só no eixo da saúde, mas também nos eixos do esporte, e da cultura e lazer.

Segundo, é preciso avançar para uma estrutura pautada na educação interprofissional. Particularmente cara para a formação no campo da saúde, e sem a qual incorrer-se-á em completo anacronismo, a interprofissionalidade constitui um dos princípios balizadores para refletir a estruturação curricular. Por sua missão e configuração organizativa, o SUS é indiscutivelmente um campo de intervenção interprofissional. Pensar currículos integrados com os demais cursos da saúde, e, inclusive, fora da saúde, permite atender uma demanda primária do trabalho em saúde, qual seja, produzir cuidado de forma colaborativa. Na experiência da UNIFESP Campus Baixada Santista, por exemplo, os discentes de Educação Física, Fisioterapia, Nutrição, Psicologia, Serviço Social e Terapia Ocupacional compartilham eixos de formação que atravessam os seis semestres iniciais do curso, a saber: ser humano em sua dimensão biológica; o ser humano e sua inserção social; e a aproximação ao trabalho em saúde. Ao ampliar essa compreensão, entendo que o trabalho no ensino formal (licenciatura), bem como nos demais eixos de formação do bacharelado (esporte, e cultura e lazer), é necessariamente campo de intervenção interdisciplinar, e que também exige trabalho colaborativo de profissionais de distintas formações.

Terceiro, faz-se necessário aprofundar a contribuição das Ciências Humanas e Sociais de maneira mais estruturada e integrada, e não apenas acessória nos currículos. A compreensão do fenômeno saúde-doença perpassa necessariamente o conhecimento e as elaborações teóricas das Ciências Sociais, Antropologia, Psicologia, Economia entre outras. Marginalizar essa discussão resultará na reprodução de uma visão reducionista do trabalho em saúde, pautado predominantemente pela racionalidade tecnicista e biomédica. Os cursos de licenciatura, historicamente, já têm apreendido, em maior volume e melhor qualidade, conceitos e teorias que nos auxiliam a compreender a sociedade. Cabe agora estender essa perspectiva na etapa de formação ampliada, bem como articulá-la a todos os eixos de formação do bacharelado.

Uma quarta preocupação, intrinsecamente relacionada à anterior, envolve a necessidade de diversificar $\mathrm{e}$ 
ampliar as compreensões do homem/corpo. A hegemonia do paradigma positivista da ciência está em xeque, e não podemos pautar nossa intervenção no campo da saúde exclusivamente sob o enfoque dos efeitos biodinâmicos do movimento humano. O olhar para a subjetividade deve ser ampliado, e a busca por intervenções balizadas na lógica da medicina baseada em evidência deve ser relativizada. Este movimento já é institucionalmente reconhecido no campo da saúde desde 2006 pela Política Nacional de Práticas Integrativas e Complementares ${ }^{12}$, bem como pelo reconhecimento das expressões atividade física/práticas corporais em publicações oficiais do Ministério da Saúde. Ao considerar toda a riqueza de possibilidades de intervir no, com e pelo corpo, a Educação Física pode ampliar substancialmente seus modos de produção de cuidado em saúde.

Quinto, é fundamental repensar o referencial pedagógico subjacente a estruturação dos currículos. A justaposição de conteúdos fragmentados, transmitidos linearmente, com pouca ou nenhuma participação dos aprendizes e desconsideração das exigências e necessidades da sociedade, já não atende às demandas do trabalho num mundo complexo e em constante mutação. Para isso, abordagens pedagógicas problematizadoras têm sido aventadas como alternativa aos modelos tradicionais de formação, particularmente na área da saúde. Tais abordagens partem da contextualização e problematização das exigências do mundo concreto, caracterizado por sua complexidade e dinamismo, e almejam a formação de sujeitos sociais mais autônomos, com competências éticas, políticas e técnicas e providos de conhecimento, raciocínio, crítica, responsabilidade e sensibilidade para as questões da vida e da sociedade. Aqui, os papeis dos docentes e discentes, a organização e desenvolvimento dos componentes curriculares e processos avaliativos passariam por uma ampla discussão. Abordagens tradicionais de ensino-aprendizagem dariam espaço para abordagens inovadoras, centradas no discente, e pautadas por elementos da realidade nos diferentes contextos de atuação profissional.

Um sexto e não menos importante aspecto, é a ênfase equilibrada nas diferentes dimensões da competência profissional: conhecimentos, habilidades e atitudes. Particularmente para o campo da saúde, destaco a necessidade de promover um compromisso ético com o SUS, com a defesa de um sistema de saúde gratuito e de qualidade como direito do cidadão e dever do Estado. A comunidade acadêmica da Educação Física pode e deve comprometer-se e unir-se aos demais coletivos do campo da saúde e da sociedade, buscando ampliar o acesso e a qualidade da atenção à saúde, e repudiando qualquer iniciativa que redunde em perda de direitos ou precarização da assistência.

Pelo exposto até aqui, e pelas características particulares da Educação Física enquanto campo de conhecimento e intervenção profissional, fica óbvio o desafio que constitui abrigar perfis de formação para os diferentes eixos de formação previstos na resolução. Caberá a cada uma das diversas comunidades acadêmicas dos cursos de Educação Física espalhadas por esse país, dialogar, refletir e agir no sentido de qualificar a formação inicial, considerando suas características, sua estrutura, o perfil do corpo docente e dos ingressantes do curso, bem como as necessidades locais e regionais em educação, saúde, esporte, cultura e lazer.

\section{Conflito de interesse}

$\mathrm{O}$ autor declara não haver conflito de interesses.

\section{Referências}

1. Santos $S$, Benedetti TRB. Cenário de implantação do Núcleo de Apoio a Saúde da Família e a inserção do profissional de Educação Física. Rev Bras Ativ Fís Saúde. 2013;17(3):188-94.

2. Silva PSC. Physical Education Professionals in the Unified Health System: an analysis of the brazilian registry of health institutions between 2013 and 2017. Rev Bras Ativ Fís Saúde. 2017;23(e0050):1-8.

3. Rodrigues JD, Ferreira D, Silva P, Caminha I, Farias Junior JC. Inserção e atuação do profissional de educação física na atenção básica à saúde: revisão sistemática. Rev Bras Ativ Fís Saúde. 2013;18(1):05-15.

4. Ivo AMS, Freitas MIF. Modos de pensar dos profissionais do ProgramaAcademia da Saúde sobre saúde e doença e suas implicações nas ações de promoção de saúde. PHYSIS/Rio de Janeiro. 2019;29(1):1-20.

5. Ayres JRCM, França Júnior I, Calazans GJ, Saletti Filho HC. O conceito de vulnerabilidade e as práticas de saúde: novas perspectivas e desafios. In: Czeresnia D, Freitas CM de, editors. Promoção da saúde: conceitos, reflexões, tendências. Rio de Janeiro: FIOCRUZ; 2003. p. 117-39.

6. Ferreira TB, Cipolotti MD, Marques BG, Luiza M, Miranda DJ. A inserção do Profissional de Educação Física nos Núcleos de Apoio a Saúde da Família : visão dos profissionais. Rev Bras Ativ Fís Saúde. 2016;21(3):228-36.

7. Fonseca SA, Menezes AS, Loch MR, Feitosa WMN, Nahas MV. Pela criação da Associação Brasileira de Ensino da Educação Física para a Saúde: ABENEFS. Rev Bras Ativ Fís Saúde. 2011;16(4):283-8.

8. Coutinho SS. Competências do profissional de Educação Física na Atenção Básica [dissertação de mestrado]. São Paulo: Universidade de São Paulo; 2011.

9. Loch MR, Dias DF, Rech CR. Apontamentos para a atuação do Profissional de Educação Física na Atenção Básica à Saúde: um ensaio. Rev Bras Ativ Fís Saúde. 2019;24(e0069):1-5.

10. Nogueira JAD, Bosi MLM. Saúde Coletiva e Educação Física: distanciamentos e interfaces. Cien Saude Colet. 2017;22(6):1913-22. 
11. Conselho Nacional de Educação. Resolução $n^{0}$ 6, de 18 de dezembro de 2018. Institui Diretrizes Curriculares Nacionais dos Cursos de graduação em Educação Física e dá outras providências. Diário Oficial da União, 2018. [citado 2019 set 03]. Disponível em: http://www.in.gov.br/materia/-/ asset_publisher/Kujrw0TZC2Mb/content/id/55877795/ do1-2018-12-19-resolucao-n-6-de-18-de-dezembrode-2018-55877683.
12. Brasil. Ministério da Saúde. Secretaria de Atenção à Saúde. Departamento de Atenção Básica. Política Nacional de Práticas Integrativas e Complementares no SUS. Brasília: Ministério da Saúde; 2006. Disponível em: http://bvsms. saude.gov.br/bvs/publicacoes/pnpic.pdf.

Recebido: 02/08/2019

Aprovado: 04/09/2019

\section{Como citar este artigo:}

Costa FF. Novas diretrizes curriculares para os cursos de graduação em Educação Física: oportunidades de aproximações com o SUS?. Rev Bras Ati Fis Saúde. 2019.24:e0067. DOI: 10.12820/rbafs.24e0067 